\title{
Follow-up after gastrectomy for cancer: the Charter Scaligero Consensus Conference
}

\author{
Gian Luca Baiocchi ${ }^{2}$ - Domenico D'Ugo ${ }^{11}$ - Daniel Coit ${ }^{8} \cdot$ Richard Hardwick $^{13}$ • \\ Paulo Kassab $^{16} \cdot$ Atsushi Nashimoto $^{24} \cdot$ Daniele Marrelli $^{19} \cdot$ William Allum $^{1}$. \\ Alfredo Berruti $^{3}$ - Servarayan Murugesan Chandramohan ${ }^{6} \cdot$ Natalie Coburn $^{7}$. \\ Santiago Gonzàlez-Moreno ${ }^{12}$ - Arnulf Hoelscher ${ }^{14}$ - Edwin Jansen ${ }^{15}$. \\ Marcis Leja $^{18}$ - Christophe Mariette ${ }^{20}$ - Hans-Joachim Meyer ${ }^{22} \cdot$ Stefan Mönig $^{14}$. \\ Paolo Morgagni ${ }^{23} \cdot$ Katia Ott $^{25} \cdot$ Shaun Preston ${ }^{27} \cdot$ Sun Young Rha ${ }^{28}$. \\ Franco Roviello $^{19}$ - Takeshi Sano ${ }^{29}$ - Mitsuru Sasako ${ }^{30}$ - Hideaki Shimada ${ }^{31}$.

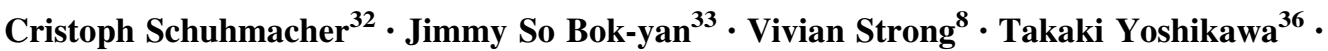 \\ Masanori Terashima $^{34}$ - Michail Ter-Ovanesov ${ }^{35}$. Cornelis Van der Velde ${ }^{37}$. \\ Maurizio Memo ${ }^{21}$ - Francesco Castelli ${ }^{4,5}$ - Sergio Pecorelli ${ }^{21,26}$ - Claudio Detogni ${ }^{9}$. \\ Yasuhiro Kodera $^{17} \cdot$ Giovanni de Manzoni $^{10}$
}

Received: 23 October 2014/Accepted: 6 June 2015/Published online: 4 July 2015

(c) The International Gastric Cancer Association and The Japanese Gastric Cancer Association 2015

\begin{tabular}{|c|c|}
\hline $\begin{array}{l}\text { Abstract } \\
\text { Purpose Presently, there is no scientific evidence sup- } \\
\text { porting a definite role for follow-up after gastrectomy for } \\
\text { cancer, and clinical practices are quite different around the }\end{array}$ & $\begin{array}{l}\text { globe. The aim of this consensu } \\
\text { an ideal prototype of follow-up } \\
\text { cer, based on shared experienc } \\
\text { the need to rationalize the diagn }\end{array}$ \\
\hline $\begin{array}{l}\square \text { Gian Luca Baiocchi } \\
\text { Gianluca.baiocchi@unibs.it }\end{array}$ & $\begin{array}{l}\text { Arnulf Hoelscher } \\
\text { arnulf.hoelscher@uk-koeln.de }\end{array}$ \\
\hline $\begin{array}{l}\text { Domenico D’Ugo } \\
\text { ddugo@rm.unicatt.it }\end{array}$ & $\begin{array}{l}\text { Edwin Jansen } \\
\text { epm.jansen@nki.nl }\end{array}$ \\
\hline $\begin{array}{l}\text { Daniel Coit } \\
\text { coitd@mskcc.org }\end{array}$ & $\begin{array}{l}\text { Marcis Leja } \\
\text { cei@latnet.lv }\end{array}$ \\
\hline $\begin{array}{l}\text { Richard Hardwick } \\
\text { richard.hardwick@addenbrookes.nhs.uk }\end{array}$ & $\begin{array}{l}\text { Christophe Mariette } \\
\text { christophe.mariette@chru-lille.fr }\end{array}$ \\
\hline $\begin{array}{l}\text { Paulo Kassab } \\
\text { paulokassab@terra.com.br }\end{array}$ & $\begin{array}{l}\text { Hans-Joachim Meyer } \\
\text { prof.hj.meyer@gmail.com }\end{array}$ \\
\hline $\begin{array}{l}\text { Atsushi Nashimoto } \\
\text { nasimoto@niigata-cc.jp }\end{array}$ & $\begin{array}{l}\text { Stefan Mönig } \\
\text { stefan.moenig@uk-koeln.de }\end{array}$ \\
\hline $\begin{array}{l}\text { Daniele Marrelli } \\
\text { marrelli@unisi.it }\end{array}$ & $\begin{array}{l}\text { Paolo Morgagni } \\
\text { morgagni2002@libero.it }\end{array}$ \\
\hline $\begin{array}{l}\text { William Allum } \\
\text { william.allum@rmh.nhs.uk }\end{array}$ & $\begin{array}{l}\text { Katia Ott } \\
\text { katja.ott@med.uni-heidelberg.de }\end{array}$ \\
\hline $\begin{array}{l}\text { Alfredo Berruti } \\
\text { alfredo.berruti@gmail.com }\end{array}$ & $\begin{array}{l}\text { Shaun Preston } \\
\text { shaun.preston@ @nhs.net }\end{array}$ \\
\hline $\begin{array}{l}\text { Servarayan Murugesan Chandramohan } \\
\text { smchandra@yahoo.com }\end{array}$ & $\begin{array}{l}\text { Sun Young Rha } \\
\text { rha7655@yuhs.ac }\end{array}$ \\
\hline $\begin{array}{l}\text { Natalie Coburn } \\
\text { natalie.coburn@sunnybrook.ca }\end{array}$ & $\begin{array}{l}\text { Franco Roviello } \\
\text { roviello@unisi.it }\end{array}$ \\
\hline $\begin{array}{l}\text { Santiago Gonzàlez-Moreno } \\
\text { gonzalez@mdanderson.es }\end{array}$ & $\begin{array}{l}\text { Takeshi Sano } \\
\text { takeshi.sano@jfcr.or.jp }\end{array}$ \\
\hline
\end{tabular}


the possibility of detecting local recurrence at a potentially curable stage.

Methods On June 19-22, 2013 in Verona (Italy), during the 10th International Gastric Cancer Congress (IGCC) of the International Gastric Cancer Association, a consensus meeting was held, concluding a 6-month, Web-based, consensus conference entitled "Rationale of oncological follow-up after gastrectomy for cancer."

Results Forty-eight experts, with a geographical distribution reflecting different health cultures worldwide, participated in the consensus conference, and 39 attended the consensus meeting. Six statements were finally approved, displayed in a plenary session and signed by the vast majority of the 10th IGCC participants. These statements are attached as an annex to the Charter Scaligero on Gastric Cancer.

Conclusion After gastrectomy for cancer, oncological follow-up should be offered to patients; it should be tailored to the stage of the disease, mainly based on crosssectional imaging, and should be discontinued after 5 years.

Keywords Gastric cancer · Follow-up · Surgery · Crosssectional imaging - Upper gastrointestinal tract endoscopy . Prognosis · Chemotherapy · Tumor markers

\section{Introduction}

The Charter Scaligero on Gastric Cancer (see http://www. gircg.it/news/the_charter_scaligero_on_gastric_cancer) has been developed by a panel of international experts who, after a Delphi technique exercise lasting several months, finally gathered at a consensus meeting in Verona (Italy) on June 22, 2013 during the 10th International Gastric Cancer Congress (IGCC). The aim of the charter is to lay the foundations for articulating a common universal vision, implementing global standards of effectiveness and efficiency in the struggle against the effects of gastric cancer, with the ultimate scope of ameliorating the quality of life of people with the disease.

One of the main debated points in the clinical path of patients with gastric cancer concerns the practice of followup after gastrectomy. Many retrospective series have demonstrated that diagnosing tumor recurrence in the asymptomatic phase does not result in an improved survival. However, clinical practice guidelines in many high-volume centers state patients should be submitted to regular clinical and instrumental postoperative checks with the aim of minimizing the nutritional sequelae of gastrectomy and the timely diagnoses of tumor recurrence. High-grade evidence on this topic is unlikely to be achieved by randomized con-

\author{
Mitsuru Sasako \\ msasako@hyo-med.ac.jp \\ Hideaki Shimada \\ hideaki.shimada@med.toho-u.ac.jp \\ Cristoph Schuhmacher \\ christoph.schuhmacher@tum.de \\ Jimmy So Bok-yan \\ jimmyso@nus.edu.sg \\ Vivian Strong \\ strongv@mskcc.org \\ Takaki Yoshikawa \\ yoshikawat@kcch.jp \\ Masanori Terashima \\ m.terashima@scchr.jp \\ Michail Ter-Ovanesov \\ termd@rambler.ru \\ Cornelis Van der Velde \\ c.j.h.van_de_velde@lumc.nl \\ Maurizio Memo \\ maurizio.memo@unibs.it \\ Francesco Castelli \\ francesco.castelli@unibs.it \\ Sergio Pecorelli \\ sergio.pecorelli@unibs.it
}

Claudio Detogni

claudio.detogni@gmail.com

Yasuhiro Kodera

ykodera@med.nagoya-u.ac.jp

Giovanni de Manzoni

giovanni.demanzoni@univr.it

1 Royal Marsden NHS Foundation Trust, London, UK

2 Surgical Clinic, Department of Clinical and Experimental Sciences, University of Brescia, Brescia, Italy

3 Medical Oncology, Department of Medical and Surgical Specialties, Radiological Sciences and Public Health, University of Brescia, Brescia, Italy

4 Medicus Mundi, Brescia, Italy

5 Infectious Diseases, Department of Clinical and Experimental Sciences, University of Brescia, Brescia, Italy

6 Department of Surgical Gastroenterology and Center of Excellence for Upper Gastro Intestinal Surgery, Madras Medical College and Rajiv Gandhi Government General Hospital, Chennai, India

7 Odette Cancer Research, Sunnybrook Research Institute, Toronto, Canada

8 Memorial Sloan Kettering Cancer Center, New York, USA

9 Verona University, Verona, Italy 
trolled trials; thus, the maximum evidence we could deal with would be reached by a consensus of experts.

Therefore, one of the 15 articles of the Charter Scaligero on Gastric Cancer has been devoted to the rationale and limits of oncological follow-up after gastrectomy for cancer.

\section{Method}

1. Appointment of a restricted working group by the IGCC Scientific Committee (December 1, 2012).

2. Production of a preliminary document by the Restricted Working Group, highlighting the main relevant data in the literature and the unsolved clinical issues, presented in the form of seven working questions (January 20, 2013) (Table. 1).

3. Restricted Working Group suggestion to the IGCC Scientific Committee of a list of names as invited experts in an enlarged working group (March 15, 2013).

4. Enlarged Working Group members confirmed their participation and acceptance of the rules of the Webbased consensus conference (April 15, 2013) (Table 2).

5. Through the Delphi method any member of the Enlarged Working Group has blindly answered the

10 1st Department of General Surgery, Borgo Trento Hospital, University of Verona, Verona, Italy

11 Department of Surgical Sciences, Catholic University, Rome, Italy

12 Anderson Center, Madrid, Spain

13 Cambridge University Hospitals Foundation Trust, Cambridge, UK

14 Department of General, Visceral and Cancer Surgery, University of Cologne, Cologne, Germany

15 The Netherlands Cancer Institute, Amsterdam, The Netherlands

16 Santa Casa Medical School, São Paulo, Brazil

17 Department of Gastroenterological Surgery 2, Nagoya University, Nagoya, Japan

18 Riga East University Hospital, University of Latvia, Riga, Latvia

19 Surgical Oncology, Department of Human Pathology and Oncology, Siena University, Siena, Italy

20 Department of Digestive and Oncological Surgery, University Hospital of Lille, Lille, France

21 University of Brescia, Brescia, Italy

22 Deutsche Gesellschaft für Chirurgie, Luisenstrasse 58/59, 10117 Berlin, Germany working questions and reviewed the statements issued by the Restricted Working Group (June 4, 2013).

6. The Charter Scaligero on Gastric Cancer, including the Annex, entitled "Rationale and limits of oncological follow-up after gastrectomy for cancer" and composed of six statements (the panel approved the merger of working questions 4 and 5 into a single statement), was reviewed in a reserved workshop held during the congress by the representative panel of specialists who participated in the exercise for formal endorsement (June 21, 2013), and it was thereafter presented and displayed for open discussion during the consensus meeting. All the participants at the 10th IGCC were allowed to sign the document (June 22, 2013).

\section{Working questions and approved statements}

\section{Question 1: Should patients be completely lost after radical surgery and possible adjuvant chemotherapy?}

\section{Statement 1}

There is no evidence that routine follow-up after curative treatment of gastric cancer (R0 resection with or without

23

Department of General Surgery, Morgagni-Pierantoni Hospital, Forlì, Italy

24 Niigata Cancer Center, Niigata, Japan

25

Department of Surgery, University of Heidelberg, Heidelberg, Germany

26 AIFA, Rome, Italy

27 The Royal Surrey County Hospital and Minimal Access Therapy Training Unit, Guildford, Surrey, UK

28 Yonsei Cancer Center, Yonsei University College of Medicine, Yonsei University Health System, Seoul, South Korea

29 Cancer Institute Hospital, Tokyo, Japan

30 Hyogo College of Medicine, Hyogo, Japan

31 Department of Surgery, School of Medicine, Toho University, Tokyo, Japan

32 Chirurgische Klinik, Technische Universität München, Munich, Germany

33 Department of Surgery, National University Hospital, Yong Loo Lin School of Medicine, National University of Singapore, Singapore, Singapore

34 Shizuoka Cancer Center, Shizuoka, Japan

35 Blokhin Center for Cancer Research, Russian Academy of Medical Sciences, Moscow, Russia 
adjuvant therapy) is associated with improved long-term survival. However, routine follow-up should be offered to all patients for oncological (detection and management of cancer recurrence), gastroenterological (endoscopic surveillance and management of postgastrectomy symptoms), research (collection of data on treatment toxicity, time to and site of recurrence, survival, and cost-benefit analyses), and pastoral (psychological and emotional support) reasons. Follow-up should include lifetime monitoring of the nutritional sequelae of gastrectomy, including, but not limited to, adequate vitamin $\mathrm{B}_{12}$, iron, and calcium replacement.

\section{Question 2: Should follow-up be done exclusively by a general practitioner instead of a surgeon, oncologist, or gastroenterologist?}

\section{Statement 2}

Follow-up should be offered by members of the multidisciplinary team who performed the initial diagnosis, staging, and treatment, including the gastroenterologist, the surgeon, the medical and radiation oncologists, and the general practitioner.

\section{Question 3: Should follow-up be differentiated on the basis of recurrence risk?}

\section{Statement 3}

Follow-up of patients following curative treatment of gastric cancer should be tailored to the individual patient, to the stage of their disease, and to the treatment options available in the event that recurrence is detected.

\section{Question 4: Should only clinical checks be done during follow-up?}

\section{Question 5: Should advanced imaging techniques be regularly prescribed during follow-up?}

\section{Statement 4}

Physical examination rarely detects asymptomatic recurrence of gastric cancer. A follow-up program intended to detect asymptomatic recurrence should be based on cross-

36 Department of Gastrointestinal Surgery, Kanagawa Cancer Center, Yokohama, Japan

37 Department of Surgical Oncology, Endocrine and Gastrointestinal Surgery, Leiden University Medical Center, Leiden, The Netherlands sectional imaging. There is no evidence that intensive cross-sectional imaging surveillance of gastric patients is associated with improved long-term survival. However, as a matter of clinical care following curative treatment of gastric cancer, it is reasonable to prescribe periodic imaging at a frequency consistent with recurrence risk. The incremental value of screening for elevated levels of biochemical markers in addition to cross-sectional imaging remains undefined.

\section{Question 6: Should upper gastrointestinal tract endoscopy be regularly prescribed during follow- up?}

\section{Statement 5}

Upper gastrointestinal tract endoscopy may be used to detect local recurrence or metachronous primary gastric cancer in patients who have undergone a subtotal gastrectomy. True local recurrence is uncommon, but if present it may be considered for resection with curative intent, especially in patients who initially presented with earlystage disease. The cost-benefit ratio of endoscopic surveillance of the anastomosis and/or gastric remnant remains undefined.

\section{Question 7: After how many years should follow-up be stopped?}

\section{Statement 6}

Routine screening for asymptomatic recurrence of gastric cancer may be discontinued after 5 years, as recurrence beyond that time is very rare.

Table 1 Working questions

\begin{tabular}{|c|c|}
\hline $\begin{array}{l}\text { Question } \\
\text { no. }\end{array}$ & Question \\
\hline 1 & $\begin{array}{l}\text { Should patients be completely lost after radical surgery } \\
\text { and possible adjuvant chemotherapy? }\end{array}$ \\
\hline 2 & $\begin{array}{l}\text { Should follow-up be done exclusively by a general } \\
\text { practitioner instead of a surgeon, oncologist, or } \\
\text { gastroenterologist? }\end{array}$ \\
\hline 3 & $\begin{array}{l}\text { Should follow-up be differentiated on the basis of } \\
\text { recurrence risk? }\end{array}$ \\
\hline 4 & Should only clinical checks be done during follow-up? \\
\hline 5 & $\begin{array}{l}\text { Should advanced imaging techniques be regularly } \\
\text { prescribed during follow-up? }\end{array}$ \\
\hline 6 & $\begin{array}{l}\text { Should upper gastrointestinal tract endoscopy be } \\
\text { regularly prescribed during follow-up? }\end{array}$ \\
\hline 7 & After how many years should follow-up be stopped? \\
\hline
\end{tabular}


Table 2 Working group members

Restricted working group members

1. Baiocchi Gian Luca (Brescia, Italy)

2. D’Ugo Domenico (Roma, Italy)

3. Kodera Yasuhiro (Nagoya, Japan)

4. Marrelli Daniele (Siena, Italy)

Enlarged working group members

1. Allum William (London, UK)

2. Asoglu Oktar (Istambul, Turkey)

3. Berruti Alfredo (Brescia, Italy)

4. Cascinu Stefano (Ancona, Italy)

5. Chandramohan SM (Chennai, India)

6. Coburn Natalie (Toronto, Canada)

7. Coit Daniel (New York, USA)

8. De Manzoni Giovanni (Verona, Italy)

9. Fujitani Kazumasa (Osaka, Japan)

10. Gonzales-Moreno Santiago (Madrid, Spain)

11. Hardwick Richard (Cambridge, UK)

12. Hartgrink Henk (Leiden, Netherlands)

13. Hoelscher Arnulf (Cologne, Germany)

14. Hyung Woo Jin (Seoul, Korea)

15. Ito Seiji (Aichi, Japan)

16. Jansen Edwin (Amsterdam, Netherlands)

17. Karpeh Martin (New York, USA)

18. Kassab Paulo (São Paulo, Brazil)

19. Katai Hitoshi (Tokyo, Japan)

20. Kolodziejczyk Piotr (Krakow, Poland)

21. Kurokawa Yukinori (Osaka, Japan)

22. Lehnert Thomas (Bremen, Germany)

23. Leja Marcis (Riga, Latvia)

24. Mansfield Paul (Houston, USA)

25. Marchet Alberto (Padova, Italy)

26. Mariette Christophe (Lille, France)

27. Meyer Hans-Joachim (Solingen, Germany)

28. Mönig Stefan (Cologne, Germany)

29. Moraes Edoardo (Bahia, Brazil)

30. Morgagni Paolo (Forlì, Italy)

31. Nashimoto Atsushi (Niigata, Japan)

32. Ott Katia (Heidelberg, Germany)

33. Pinto Carmine (Bologna, Italy)

34. Preston Shaun (Guildford, UK)

35. Rha Sun Young (Seoul, Korea)

36. Roviello Franco (Siena, Italy)

37. Sano Takeshi (Tokyo, Japan)

38. Sasako Mitsuru (Hyogo, Japan)

39. Shimada Hideaki (Tokyo, Japan)

40. Schuhmacher Cristoph (Munich, Germany)

41. So Jimmy (Singapore)

42. Strong Vivian (New York, USA)

43. Ter-Ovanesov Michail (Moscow, Russia)
Table 2 continued

44. Terashima Masanori (Shizuoka, Japan)

45. van de Velde Cornelis (Leiden, Netherlands)

46. Yang Han-Kwang (Seoul, Korea)

47. Yoshikawa Takaki (Yokohama, Japan)

48. Zaniboni Alberto (Brescia, Italy)

\section{Discussion}

Tumor recurrence after curative therapy for gastric cancer is unfortunately common, and the great majority of cases are incurable. Performing regular postoperative instrumental checks is of unproven value. However, high-volume cancer centers usually offer their patients some form of regular follow-up after radical therapy. The rationale for this is threefold; to manage the quality of life and nutritional aspects of gastrectomy, to provide pastoral support for the patient and their family, and to conduct audit/research. The effects of gastrectomy for patients are both predictable (i.e., weight loss) and unpredictable (i.e., dumping). It is therefore imperative that they are seen regularly during the first year after surgery to provide support and advice, particularly regarding nutrition. Presently, there is little a clinician can offer a patient with recurrent gastric cancer except palliative chemotherapy. Soon, biomedical research will hopefully provide therapeutic weapons for metastatic cancer patients and/or relapsing patients. All clinical teams have an obligation to monitor their outcomes with the aim of improving standards, and this process relies on the routine audit of outcomes. All these aspects of a high-quality service require patients to be offered regular and timely access to the specialist multidisciplinary team.

This article presents the results of an international consensus conference of experts participating in a Webbased program lasting several months and finally concluded in a reserved open-discussion session during the 10th IGCC held in Verona in June 2013. The board of experts recognized that follow-up is good clinical practice and should to be offered to all patients for the reasons already mentioned. Follow-up should be individualized to the patient and appropriate for the patient and the health care setting (i.e., video-linking may be the easiest way to contact patients who live far from their hospital). Followup should consist of clinical review and cross-sectional imaging with or without upper gastrointestinal tract endoscopy, and should be discontinued after 5 years.

The statements of this consensus of experts are included in the Charter Scaligero on Gastric Cancer as an annex related to Article 13 ("The role of the "follow up" in the management of gastric cancer"), which states: "The 
appropriate management of the disease is fundamental not only for improving the patients' quality of life but also in order to decrease unnecessary costs for the health systems. A panel of experts who participated in the 10th IGCC have elaborated a vision and reached a consensus on a number of statements that are intended as a guide of principles that would be of help to better manage the follow up of the disease after surgery. The Institutions and Professionals who endorsed this Charter and the "statements on the follow up" commit themselves to implement methodologies that will be reviewed, on the bases of evidence, in future congresses with the scope to come in the future to common approaches."

The Charter Scaligero on Gastric Cancer is currently being promoted to the cultural, political, and administrative institutions dealing with health worldwide. It is expected it will be reevaluated every 2 years.

\section{Compliance with ethical standards}

Conflict of interest The authors declare that they have no conflict of interest. 